\title{
Global action urged in response to new breed of drug-resistant bacteria
}

Previously published at www.cmaj.ca

$\mathrm{T}$ he World Health Organization (WHO) and public health agencies around the world must significantly ramp up screening and surveillance of a new breed of drugresistant bacteria carrying the gene for New Delhi metallo-beta-lactamase-1 (NDM-1), warned a panel of expert micropathologists at the American Society for Microbiology annual meeting in Boston, Massachusetts in September.

Clinicians in Canada and other nations with substantial volumes of travellers from South Asia should also start asking patients whether they "have been admitted or travelled in the Indian subcontinent," urged Dr. Johann Pitout, professor of pathology and laboratory medicine at the University of Calgary in Alberta.

Patients should also be advised to disclose to their doctors all recent travel to south Asia, Pitout said during a Sept. 13 press conference on "NDM-1: The New Superbugs \#ICAAC" (webcast at: www.microbeworld.org/index .php?option $=$ com_jlibrary \& view $=$ article $\& \mathrm{id}=4776 \&$ Itemid=54).

NDM-1 is an enzyme that makes bacteria resistant to a broad range of beta-lactam antibiotics, including carbapenem antibiotics, which are among the last-case treatments for infection when other drugs fail.

Some isolates of the bacteria carrying NDM-1 are impervious to all known drugs, Timothy Walsh, professor of medical microbiology at Cardiff University in Wales, warned. "These plasmids are quite promiscuous."

"We have all the ingredients for the worldwide spread of this problem," added Dr. Patrice Nordmann, chief of the department of bacteriology-virology at the Hôpital Bicêtre in La Kremlin-Bicêtre, France, and professor in clinical microbiology at the South-Paris Medical School.

NDM-1 is now widely disseminated

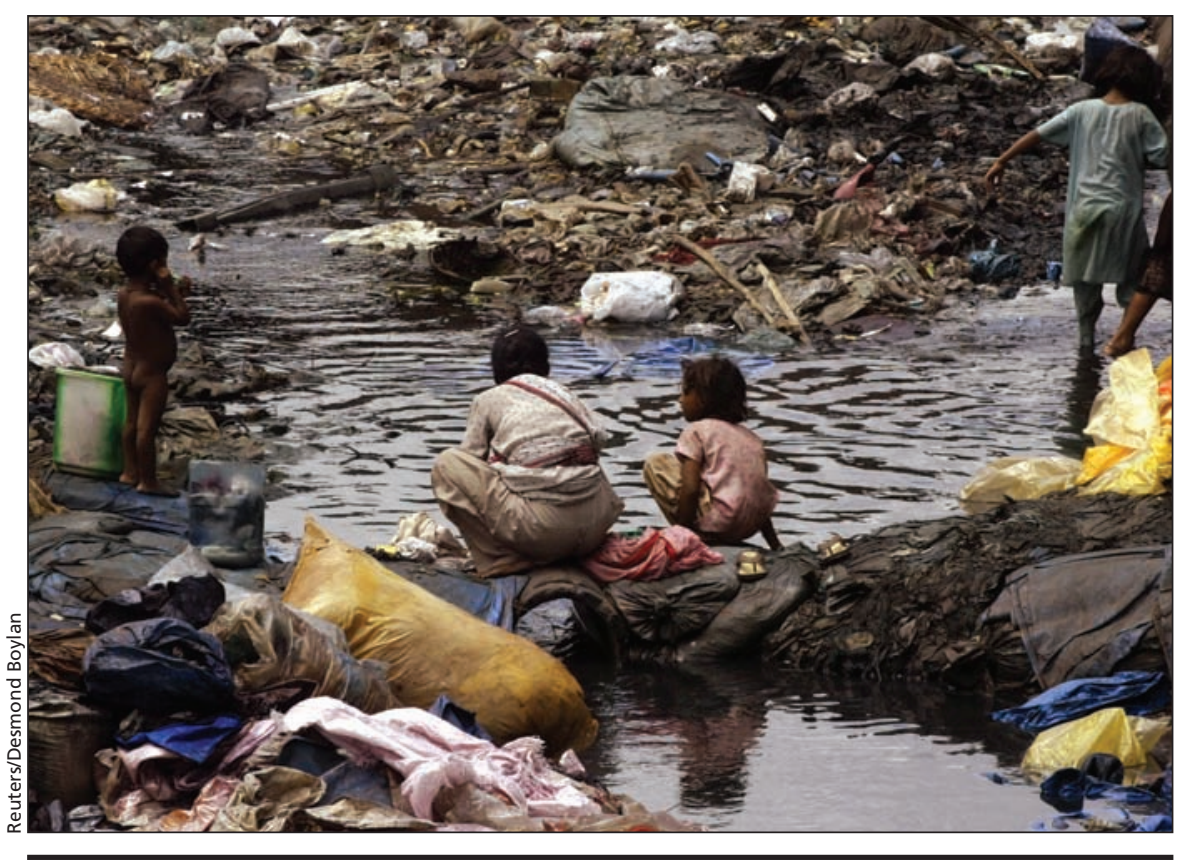

NDM-1 is widely disseminated in India because of contaminated sewage and water.

throughout the Indian subcontinent because of contaminated sewage and water, and as a consequence, the threat is community-based, Nordmann added. "Our main concern is the size of the reservoir, which is 1.3 billion people," he said.

The threat is also global.

Because communities in South Asia have extensive links with diaspora communities worldwide, NDM-1 is now moving widely along air travel corridors, Nordmann and Pitout said.

Nordmann noted that NDM-1 has been found in samples from labs in numerous countries and that public health officials in France, Singapore, Japan and China are already acting to counter the threat of NDM-1. France, for example, has begun screening patients who have been admitted to foreign hospitals for NDM-1.

"This needs to be done immediately worldwide," he advised.

Nordmann also urged WHO action. "At the WHO, there is nothing for the surveillance of any emerging antibiotic resistance. There is a very nice network on flu and malaria and tuberculosis, but nothing on antibiotic resistance, which is incredible."

"We need global policies that need to be adhered to with respect to antibiotic use and surveillance," said Walsh, adding that treatment prospects for a bacteria resistant to all drugs are grim.

Pharmaceutical options are meager and limited, he said. "The trouble is we've got one, or two that look promising, and what we need is six or eight to cover our options. And the trouble is that as soon as these compounds are marketed in about two or three years time, they are going to be used like sweets in some countries and resistance will ensue."

Pitout described two cases of NDM1 in Canada, involving patients in British Columbia and Alberta who had visited hospitals in India and developed urinary tract infections before being transferred back to Canada. 
One of the patients was infected with a clonal version of NDM-1 that was identical to one later discovered in an Australian patient with whom he'd had no contact, reinforcing the proposition that NDM-1 is capable of rapid and widespread clonal duplication.

Pitout also warned the NDM-1 poses the greatest risk for those with hard-totreat infections, such as upper urinary tract infections, and that it has now been identified in Escherichia coli, a very common pathogen.

"If this does become common, it's going to lead to a lot of failure of treatment," he said, noting that "E. coli causing urinary tract infections is probably the second most common infection that a general practitioner will see in his or her lifetime, respiratory tract infection being the most common."

"There is a potential chance that we will have a very resistant bug causing a very resistant type of infection, which general practitioners will meet on daily basis. And that to me is the real issue, because general practitioners are not qualified really to treat such multiresistant types of bacteria, especially in the community. And that to me is really the take-home message," Pitout added.

Thus far, the Public Health Agency of Canada (PHAC) has responded to the NDM-1 threat with a statement that downplays concerns: "Generally, the public health risk to Canadians is very low. Research shows all of the Canadian cases have acquired their infections in hospital settings while undergoing medical treatment in India or Pakistan" (www.phac-aspc.gc.ca/amrram/ndm/index-eng.php\#q4).

The agency also noted that "provinces and territories are not required to report cases of NDM-1 to PHAC; however PHAC encourages hospitals to report healthcare-associated infections to their province or territory."

The United Kingdom's Health Protection Agency issued a resistance alert in January stating that, given the patterns of travel and migration, "it is vital to detect producers and to prevent their onward transmission." - Paul Christopher Webster, Toronto, Ont.

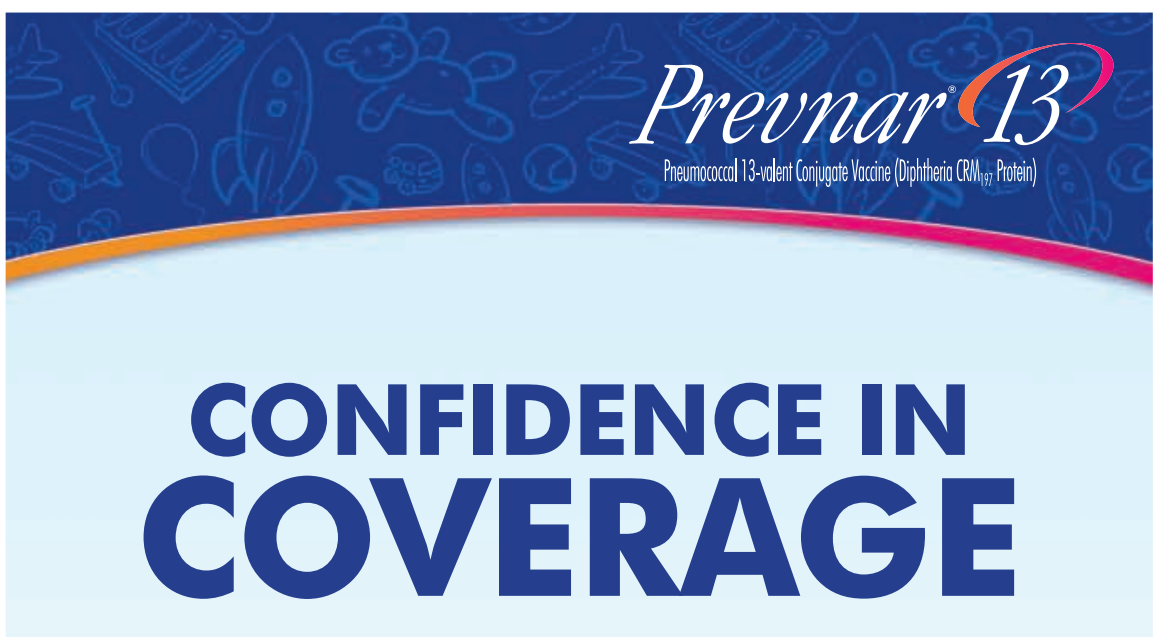

\section{Providing the broadest coverage of S. pneumoniae serotypes indicated in a pneumococcal conjugate vaccine $e^{n, 2,3}$}
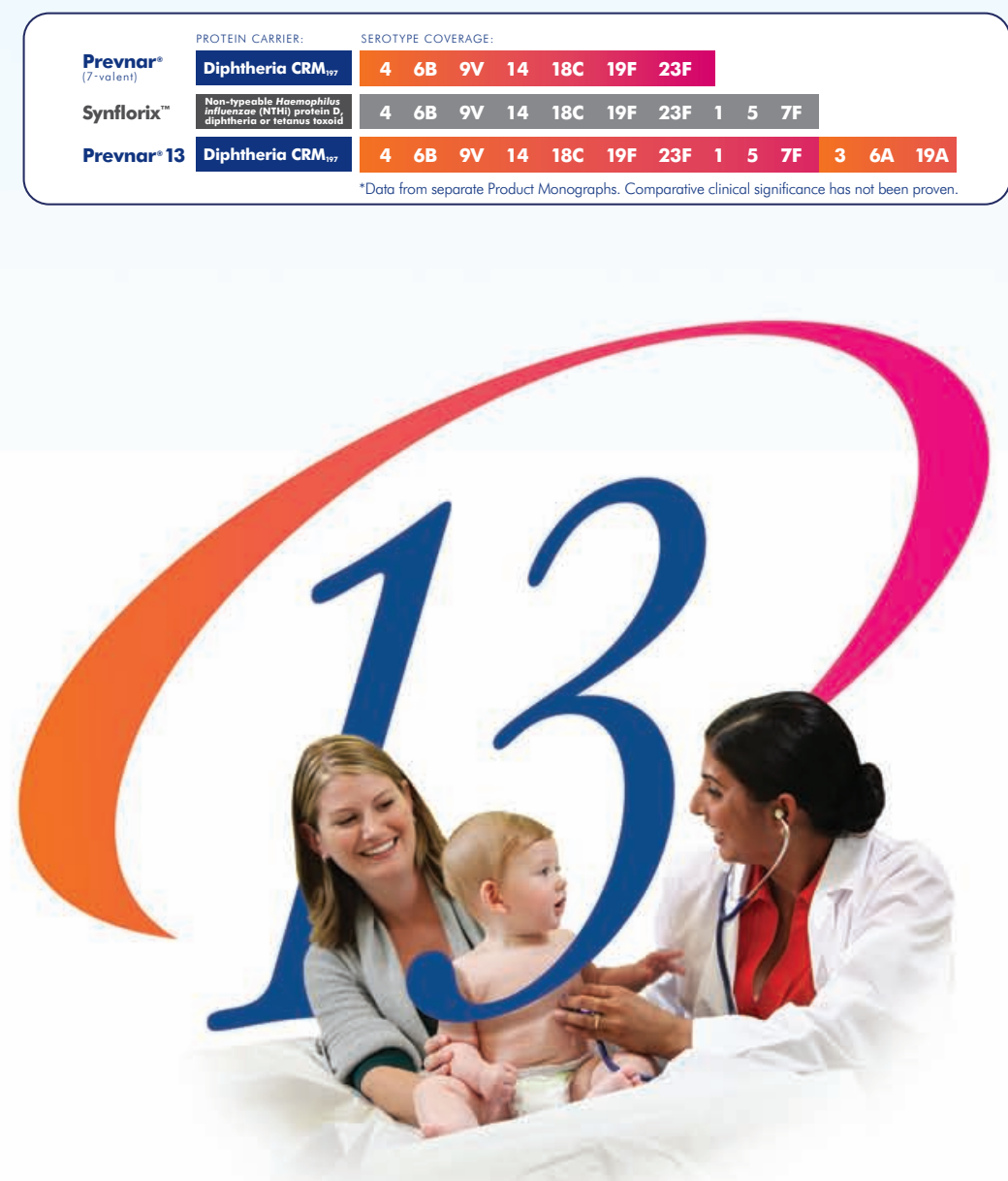

Wyeth $\stackrel{\text { Mabser }}{\text { RADE }}$

() 2010 Wyeth Canada
Montréal, Canada H4R 1J6 